\title{
How can Canada improve worsening wait times?
}

Cite as: CMAJ 2020 September 14;192:E1079-80. doi: 10.1503/cmaj.1095895

Posted on cmajnews.com on August 28, 2020

Part one of Waiting for Change, a special series on access to care in Canada.

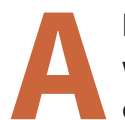

bout one in three Canadians who need joint replacements or cataract surgery don't get those procedures within recommended times. Wait times for prostate cancer and lung cancer surgeries are increasing. And those are just the delays we know about - for most health services, beyond a handful of priority procedures, there is scant information about how long patients are waiting to access care.

Year after year, it's been the same story - that is, until coronavirus disease 2019 (COVID-19) compounded Canada's access issues. As thousands of patients across the country face additional delays in care, "I'm not sure we're ever going to catch up," says cardiologist and wait time expert Dr. Chris Simpson.

Together with family physician Dr. Kamila Premji and Robin McGee, a cancer patient whose care was delayed due to the COVID-19 slowdown, Simpson spoke to CMAJ about how Canada can avert an access crisis in the months and years ahead. Their comments have been edited for clarity and length.

\section{CMAJ: Why are wait times so bad in Canada?}

Simpson: There are bottlenecks everywhere. A lot of delays are driven by the fact that hospitals operate at very high capacity because there are large numbers of patients requiring alternate levels of care [who have nowhere else to go]. The interconnectedness of all the sectors in health care has been underappreciated, and siloed funding has inhibited the kinds of cross-sector discussions that could improve patient flow. A lot of people still manage wait lists as a stack of paper on the side of their desks, which leads to inefficiency. And we know that a significant amount of care that's provided

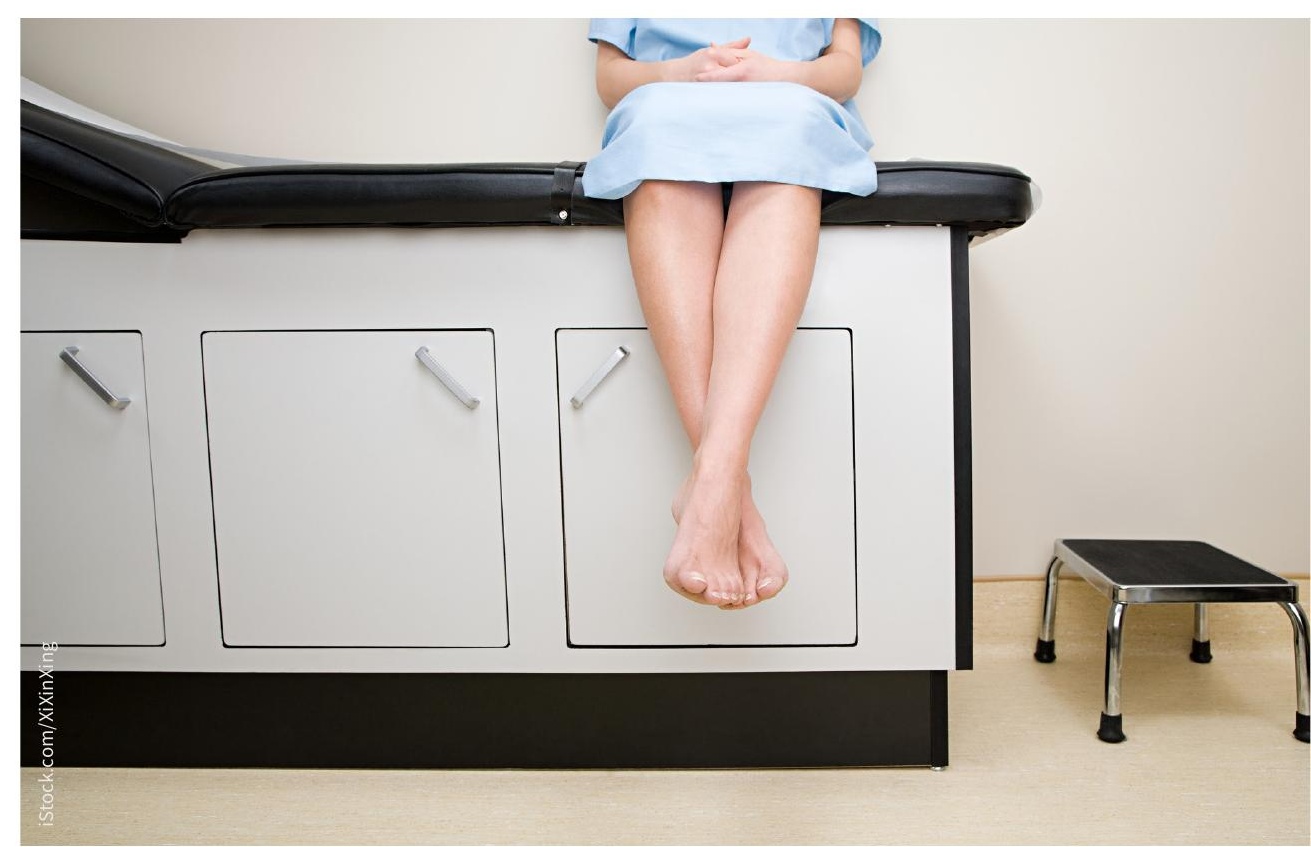

COVID-19 has compounded longstanding access problems but may compel change.

is low value - we haven't really made any serious effort to address that.

Premji: There's a limited number of specialists, limited operating room time allocated to surgeons, limited machines for advanced imaging, and that keeps patients on wait lists for long periods. The waits for specialist care and diagnostic imaging in turn increase the number of contacts patients need to have with primary care while they're waiting for the next step in addressing their problems.
We also have poorly integrated health information technology that creates a lot of administrative burdens and decreases the number of patients we can take on. The amount of time I spend on administrative work has increased over the years to the point that I'm now doing close to 
effort to communicate with my cancer doctors. There was no getting through. I waited three months for treatment of any kind, when normally chemotherapy should be initiated within weeks, and five months to even speak to a surgeon.

\section{CMAJ: Is part of the problem that} Canadians accept these waits as the price of publicly funded health care?

Premji: The fact that the United States, our closest neighbour, has such a problematic health care system creates a bit of complacency at every level, from the patients to the physicians to the policymakers and administrators. I also think some people don't realize how long the queues are until they're in one - it's an abstract concept until you hear, like one of my patients did recently, it's going to take two years to get cataract surgery.

Simpson: Canadians have accepted that some delay is reasonable in order to have an equitable health care system, and that's not necessarily a bad thing. But one of the things we're doing in Kingston now is a major project to guarantee that every patient who is referred to a specialist waits no more than three months. In my view, this is what organizations need to take on $-\mathrm{a}$ sense that we have a responsibility to the patients we serve and if we can't provide a three-month guarantee, then we're not doing it right. We just haven't put our feet to the fire on this stuff as much as we could.

McGee: In the United Kingdom, [certain] urgent cancer cases must receive treatment in two weeks. Not to say there aren't people who fall through the cracks, but they have a system in place that recognizes the need for timely care. Here, it just doesn't seem to have [the same] priority, and with COVID-19 thrown in the mix, there's an attitude like, "People can wait."
CMAJ: What are some obvious fixes to the access challenges Canadians are facing?

Simpson: One of the things that has been underutilized has been single entry models [where patients enter a single queue for a certain specialty or procedure]. If we distributed patients to the first available provider, rather than having individual lineups for different providers, we could gain 20\%-30\% efficiency. That's why Walmart does it that way - it's far more efficient to have a single queue for all the cashiers.

Premji: Lots of time is spent trying to organize tests and referrals only to hear back, "My wait is too long. Send them somewhere else." Especially during the pandemic, we're having to redirect referrals multiple times. Being able to see the estimated wait time for each specialist or having a centralized queue would be fantastic. Support for team-based care with allied health providers like nurse practitioners and social workers and psychologists could also help share some of the work - [funding for that model] has been frozen for years in Ontario.

McGee: We need to empower patients with information. The silence of the system is painful. It is destructive to patient care. And to me, it seems you don't have to be silent. Every patient who was awaiting a heart transplant or something serious should have gotten a phone call saying, "This is what's going to happen with your case with the cancellations. You're going to have to wait this long, but I hear you, I see you and I haven't forgotten."

\section{CMAJ: What have been the barriers to meaningful reform?}

Simpson: We haven't really embraced the notion that we need to measure and publicly report wait times beyond a few politically advantaged procedures, like hip and knee and cataract surgery. If you're not willing to report and publicly make it very clear where the problems are, then clearly there's not going to be any momentum to make change.

Premji: Part of it is money. [When it comes to access to family doctors,] there's a distribution problem and a shortage of physicians, not in total numbers, but in the number providing comprehensive primary care. Especially in Ontario, where there has been a freeze on funding for team-based models, new graduates don't want to go into solo practice so they are going into more focused practices or doing walkin care or locum work, so they're not necessarily adding a comprehensive family doctor to the system.

\section{CMAJ: We know COVID-19 has}

created new challenges in access to care, but what opportunities do you see it creating?

Premji: We've learned that we can do more by virtual care than we previously had been doing. If we look at U.S. data, virtual care actually created new health care utilization, far more than it replaced face-to-face care. It's unclear whether that reflects previously unmet needs or new demand.

McGee: I like to think telemedicine will expedite access because people can be assured of [more direct] communication. A wise nurse once told me, "Communication is medicine. When we fail to communicate with the patient, we're depriving them of important reassurance, guidance and care."

Simpson: There's nothing like a crisis to make things happen. [In the past,] a lot of people have said we can't move patients requiring alternative levels of care out of hospitals. Well, guess what? We did it in about four weeks. The crisis created the political will to make it happen. We're not going to be able to do that for wave two because long-term care capacity has been decreased... so this is a perfect time for us to double down on appropriateness. We need to look at every person on the list for a procedure and ask, is there an alternative?

\section{Lauren Vogel, CMAJ}

